\title{
Testicular and Hematopoietic Toxicity of 2-Bromopropane, a Substitute for Ozone Layer-Depleting Chlorofluorocarbons
}

\author{
Gaku IChiHARA ${ }^{1}$, Nobuyuki Asaeda ${ }^{2}$, Toshihiko Kumazawa ${ }^{2}$, Yoshiaki TAGawa ${ }^{2}$, \\ Michihiro KamiJima ${ }^{1}$, Xiaozhong $\mathrm{YU}^{1}$, Hidetaka Kondo ${ }^{1}$, Tamie NaKAJIMA ${ }^{3}$, Junzoh \\ $\mathrm{KITOH}^{4}$, Il Je YU ${ }^{5}$, Young Hahn MoON ${ }^{5}$, Naomi HisanaGa ${ }^{6}$ and Yasuhiro TAKeUCHI

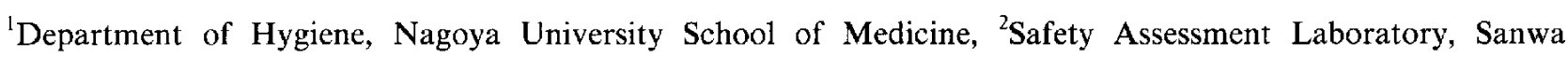 \\ Kagaku Kenkyusho Co., Ltd., ${ }^{3}$ Department of Hygiene, Shinshu University School of Medicine, ${ }^{4}$ Institute for \\ Laboratory Animal Experiment, Nagoya University School of Medicine, ${ }^{5}$ Industrial Health Research Institute, \\ Korea Industrial Safety Corporation, and ${ }^{6}$ National Institute of Industrial Health
}

\begin{abstract}
Testicular and Hematopoietic Toxicity of 2-Bromopropane, a Substitute for Ozone LayerDepleting Chlorofluorocarbons: Gaku IcHIHARA, et al. Department of Hygiene. Nagoya University School of Medicine--In 1995, unexpected amenorrhea, oligozoospermia and anemia were discovered in Korean workers exposed to solvents containing 2-bromopropane which was a substitute for chlorofluorocarbon. We aimed to determine experimentally the testicular and hematopoietic toxicity of 2 -bromopropane in male rats. Thirty-six Wistar male rats were divided into four groups of nine each. The rats were exposed to $300,1,000$ and $3,000 \mathrm{ppm} \mathrm{2-}$ bromopropane or only fresh air, respectively, $8 \mathrm{hr}$ a day, 7 days per week. The $300 \mathrm{ppm}$ and $1,000 \mathrm{ppm}$ groups were exposed for 9 weeks, but the 3,000 ppm group's exposure was discontinued and three rats in this group were dissected after 9-11 days' exposure because of serious illness. The others were dissected at the end of the experiment. At $300 \mathrm{ppm}$ or over, the testicular and epididymal weights per body weight, epididymal sperm count, motile sperm percentage and the number of erythrocytes and platelets had decreased compared to the control. Histopathologically, all types of germ cells decreased in the $300 \mathrm{ppm}$ group. Germ cells were absent but Sertoli cells still remained in the 1,000 $\mathrm{ppm}$ and 3,000 ppm groups at the end of the experiment. Spermatogonia were absent and the number of spermatocytes decreased in the $3,000 \mathrm{ppm}$ group
\end{abstract}

Received Aug 19, 1996; Accepted Oct 22, 1996

Correspondence to: G. Ichihara, Department of Hygiene, Nagoya University School of Medicine, 65 Tsurumai-cho, Showa-ku, Nagoya 466, Japan

A part of this article has appeared in this journal as a rapid communication, Ichihara $G$, et al. Testicular Toxicity of 2Bromopropane. J Occup Health 1996; 38: 205-206. rats sacrificed after 11 days' exposure. Sertoli cell vacuolations were marked in two of these three rats. Bone marrow was hypocellular in the $1.000 \mathrm{ppm}$ group and in all the rats in the $3,000 \mathrm{ppm}$ group. These results clearly showed that 2-bromopropane had a testicular and hematopoietic toxicity in male rats.

(J Occup Health 1997: 39:57-63)

Key words: 2-bromopropane, Testicular toxicity, Hematopoietic toxicity. Chlorofluorocarbon substitute, Sertoli cell-only syndrome

The production of chlorofluorocarbons (CFCs) is now going to be drastically diminished all over the world, because these chemicals have a great potential to destroy the ozone layer and to warm the earth's environment. This countermeasure to CFCs has, on the other hand, resulted in the introduction of various alternatives into the workplace. In July, 1995 unexpected health disorders were discovered in Korean workers exposed to solvents containing 2bromopropane (CAS No. 75-26-3) in an electronic machine components factory. An epidemiological survey ${ }^{1)}$ conducted by the Korea Industrial Safety Corporation in August of that year, disclosed that (1) amenorrhea occurred in $17(68 \%)$ of 25 females and oligozoospermia in six $(75 \%)$ of eight males, accompanied by anemia in six females and one male; (2) amenorrhea appeared shortly after the introduction of 2-bromopropane as a substitute for 1,1,2-trichloro-1,2,2-trifluoroethane, one of the CFCs, and (3) these health disorders were not found among reference workers. The above evidence suggested that 2-bromopropane might be the 
causative agent. 2-Bromopropane is an existing chemical used as an intermediate in the production of various chemicals. The toxicity of 2-bromopropane, however, has not been reported except in the acute toxicity test ${ }^{2)}$, and its threshold limit value has not been proposed by the Korean Government, the Japan Society for Occupational Health or the American Conference of Governmental Industrial Hygienists Inc. (ACGIH).

The aim of this study is to determine experimentally the testicular and hematopoietic toxicity of 2bromopropane. We examined the effects of 2bromopropane on the weights and morphology of organs, the sperm parameters and hematological indices in male rats. Some of the data have already been reported in a rapid communication ${ }^{3)}$.

\section{Materials and Methods}

2 -Bromopropane $(99.4 \%$ purity) was kindly supplied by Tosoh Co., Japan. Thirty-six Wistar male rats (specific pathogen-free, 9 weeks) were purchased from SLC (Shizuoka Laboratory Animal Center, Japan). The animals were housed and adapted to the circumstances for 4 weeks and divided into four groups of nine rats each. The environment was kept on a $12 \mathrm{hr}$ light-dark cycle (lights on at 9:00 and off at 21:00), and maintained at $22-25^{\circ} \mathrm{C}$ and $57-60 \%$ relative humidity. Three groups were then exposed to $300,1,000$ or $3,000 \mathrm{ppm} 2$ bromopropane, respectively, in stainless steel chambers $(80 \times 80 \times 58 \mathrm{~cm})$. The maxium concentration of $3,000 \mathrm{ppm}$ was set to be less than the reported $\mathrm{LC}_{50} 36,000 \mathrm{mg} / \mathrm{m}^{3}(7,159 \mathrm{ppm})^{2)}$ or $31,171 \mathrm{ppm}, 4$ $\mathrm{hr}^{4)}$. The common ratio was put at about 3 . The control group was given only fresh air in a similar chamber. The inhalation exposure was performed eight hours a day, 7 days per week. The $300 \mathrm{ppm}$ and $1,000 \mathrm{ppm}$ groups were exposed for 9 weeks. After 9-11 days' exposure, all the rats in the 3,000 ppm group became seriously ill, then their exposure at $3,000 \mathrm{ppm}$ was discontinued. Three in the 3,000 ppm group were sacrificed and the testes and femur were dissected from them 16-17 hr after the cessation of 11 days' exposure. The other six rats in the $3,000 \mathrm{ppm}$ group were exposed to fresh air until the end of the experiment. Food and water were provided ad libitum. The inhalation exposure system was described elsewhere in detail ${ }^{5,6)}$. The regulated volume of solvents was evaporated and mixed with a larger volume of clean air to achieve the desired concentration. The vapor concentrations in the chamber were measured by gas chromatography and controlled to within $\pm 5 \%$ of the target concentration by means of a personal computer, but the inhalation system was modified for the present experiment in the following three ways: To prevent hydrolysis of 2-bromopropane into isopropyl alcohol and hydrogen bromide, (1) 2-bromopropane was evaporated at room temperature without heating, and (2) compressed air which evaporated 2bromopropane was dried with an electronic air dryer (EAD-70, Yaezaki Kuatsu Co., Ltd.). Hydrogen bromide was not detected in a chamber with a detector tube (detection limit, $0.05 \mathrm{ppm}$ ). To prevent the reaction of 2-bromopropane with aluminium, (3) the aluminium evaporator was replaced with one made of stainless steel.

The testes, epididymides, prostate, seminal vesicle, femur, liver and kidneys were dissected out from the remaining six rats in the 3,000 ppm group and the rats in the other groups at the end of the experiment. The rats were weighed and anesthetized with sodium pentobarbital $(50 \mathrm{mg} / \mathrm{kg}$ ). They were exsanguinated and the blood was collected with a syringe by aortic puncture.

The dissected organs were weighed, and the left testis and epididymis were fixed in Bouin's solution and the prostate, seminal vesicle, femur, liver and kidneys were fixed in $10 \%$ neutral buffered formalin for histopathological studies. The femur was decalcified after the fixation. The specimens were processed and embedded in paraffin. Tissue sections of testis and epididymis were stained with periodic acid-Schiff's reagent (PAS) and those of other organs with hematoxylin and eosin (H-E).

Sperm were collected as quickly as possible after the rat was killed. Sperm suspensions were prepared by mincing the right cauda epididymidis in $2.5 \mathrm{~m} /$ of Hank's solution kept at $37^{\circ} \mathrm{C}$, pipetting the suspension and filtering it through gauze. A fraction of the suspension was diluted with Hank's solution kept at $37^{\circ} \mathrm{C}$. Active sperm per hundred sperm were counted with an erythrocytometer (Neubauer type) under a light microscope. Another fraction of the sperm suspension was diluted with saline containing $0.5 \%$ formalin for determination of the sperm count. Sperm shape was examined according to the method of Wyrobek and Bruce $(1975)^{7}$ and Eyden and Maisin $(1978)^{8)}$.

The following hematologic parameters were determined: erythrocyte counts, hemoglobin concentration, hematocrit, mean corpuscular volume (MCV), mean corpuscular hemoglobin (MCH), mean corpuscular hemoglobin concentration (MCHC), total leucocyte count and platelet count (with an F-800 Toa Microcell Counter, Toa Medical Electronics).

Statistical comparisons of the exposed groups with the control were performed by analysis of variance (ANOVA) followed by Dunnett's multiple 
Table 1. Body weight and organ weights in rats exposed to 2-bromopropane at the end of the experiment

\begin{tabular}{|c|c|c|c|c|c|}
\hline \multicolumn{2}{|c|}{ Group } & \multirow{2}{*}{$\frac{\text { Control }}{9}$} & \multirow{2}{*}{$\frac{300 \mathrm{ppm}}{9}$} & \multirow{2}{*}{$\frac{1,000 \mathrm{ppm}}{9}$} & \multirow{2}{*}{$\frac{3,000 \mathrm{ppm}}{6}$} \\
\hline Number of rats & & & & & \\
\hline Body weight & (g) & $491 \pm 21$ & $458 \pm 31.4^{*}$ & $402=19.7^{* *}$ & $468 \perp 12.1$ \\
\hline \multicolumn{6}{|c|}{ Absolute organ weight } \\
\hline Epididymides & (g) & $1.18 \pm 0.11$ & $0.91 \pm 0.06^{* *}$ & $0.69 \pm 0.04^{* *}$ & $0.70 \pm 0.04^{* *}$ \\
\hline Testes & (g) & $3.30 \pm 0.24$ & $1.54 \div 0.12^{* *}$ & $1.36 \pm 0.09^{* *}$ & $1.27 \pm 0.17^{* *}$ \\
\hline Prostate & (g) & $0.90 \pm 0.16$ & $0.72=0.19^{*}$ & $0.44 \perp 0.10^{* *}$ & $0.67 \pm 0.07^{*}$ \\
\hline Seminal vesicles & (g) & $2.06 \pm 0.18$ & $1.72+0.14^{* *}$ & $1.24 \pm 0.21^{* x}$ & $1.74 \pm 0.21^{* *}$ \\
\hline Liver & (g) & $15.43 \pm 1.48$ & $14.48 \pm 1.22$ & $13.36 \pm 1.16^{* *}$ & $14.71 \pm 0.81$ \\
\hline Kidneys & (g) & $2.95 \pm 0.21$ & $2.70 \pm 0.16^{*}$ & $2.45 \pm 0.17^{* *}$ & $2.82 \div 0.14$ \\
\hline \multicolumn{6}{|c|}{ Relative organ weight } \\
\hline Epididymides & (mg/g body) & $2.41 \pm 0.20$ & $1.99 \pm 0.15^{* *}$ & $1.72 \pm 0.12^{* *}$ & $1.49 \pm 0.09^{* *}$ \\
\hline Testes & (mg/g body) & $6.72 \pm 0.45$ & $3.37 \pm 0.36^{* *}$ & $3.39 \pm 0.31^{* *}$ & $2.70 \pm 0.32^{* *}$ \\
\hline Prostate & (mg/g body) & $1.85 \pm 0.41$ & $1.57+0.43$ & $1.10 \perp 0.23^{* *}$ & $1.44 \pm 0.18$ \\
\hline Seminal vesicles & (mg/g body) & $4.21 \pm 0.36$ & $3.76 \pm 0.36$ & $3.09 \perp 0.51^{* *}$ & $3.71 \pm 0.46$ \\
\hline Liver & (mg/g body) & $31.39 \pm 2.12$ & $31.61 \pm 1.01$ & $33.16 \pm 1.43$ & $31.42 \pm 1.44$ \\
\hline Kidneys & (mg/g body) & $6.02 \pm 0.36$ & $5.91 \pm 0.45$ & $6.10 \perp 0.34$ & $6.02 \pm 0.29$ \\
\hline
\end{tabular}

The exposure in the 3,000 ppm group was discontinued after 9-11 days' exposure. Six rats in the 3,000 ppm group were then given only fresh air unlil the end of the experiment. The weights of epididymides, lestes and kidneys are expressed as the sum of right and left organs. Values are the means \pm standard deviations for each group. Asterisks indicate that the value was significantly different from the control ( ${ }^{*} p<0.05,{ }^{* *} \mathrm{p}<0.01$, Dunnetts' multiple comparjson).

comparison method. The numbers of abnormal sperm in the $300 \mathrm{ppm}$ and control groups were compared by Student's t-test, because the number of abnormal sperm could not be estimated in the 1,000 ppm and 3,000 ppm groups.

\section{Results}

The mean and standard deviations of daily exposure concentrations of 2-bromopropane were $302 \pm$ $17 \mathrm{ppm}, 1,035 \pm 35 \mathrm{ppm}$, and 2,964士165 ppm (mean $\pm S D$ ), respectively. Body weight gain was suppressed in a dose-dependent manner by 2bromopropane exposure (Fig. 1). Mean body weight in the 3,000 ppm group fell throughout the exposure period, but it recovered after the exposure ended. It became comparable to that in the 300 ppm group or the control at the end of the experiment (Fig. 1 and Table 1).

At $300 \mathrm{ppm}$ and over, absolute weights of testes, epididymides, prostate and seminal vesicle decreased in comparison with the control (Table 1). Because body weight was significantly lower in the 300 and $1,000 \mathrm{ppm}$ groups than in the control, the relative weights of organs to body weight are shown in Table 1. 2-Bromopropane reduced the relative weights of the genital organs, but not those of liver and kidneys.

Exposure of the six surviving rats in the 3,000 ppm group was discontinued after 9-10 days' exposure. This short-term exposure resulted in a weight loss in the testes comparable to or more than that
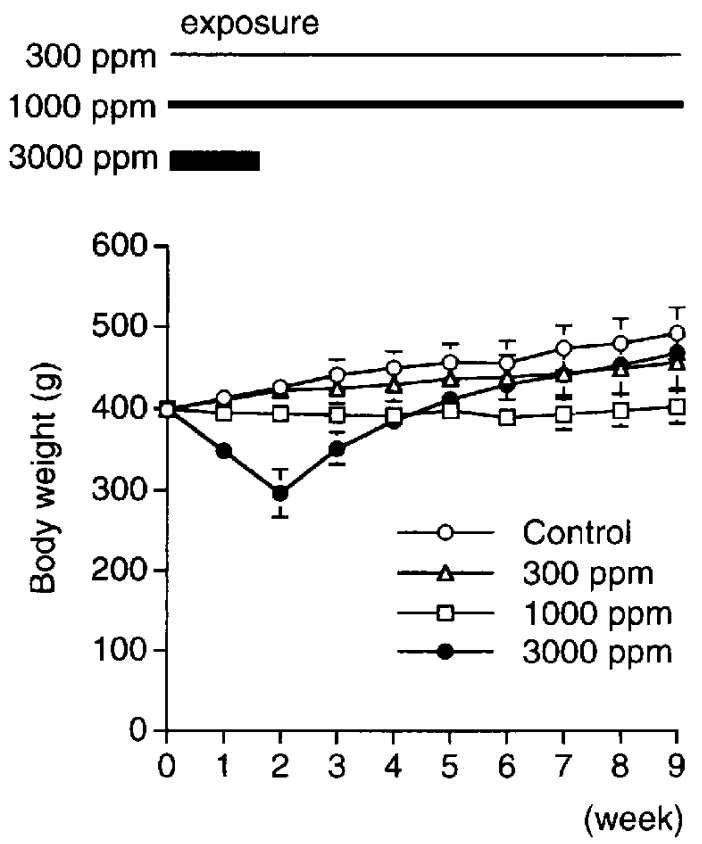

Fig. 1. Time course of body weight (Means =S.D.). The exposure in the 3,000 ppm group was discontinued after 9 -11 days' exposure. Three rats in the 3,000 ppm group were killed 16-17 hr after cessation of exposure and the six surviving rats were given only fresh air until the end of the experiment

at 1,000 ppm for 9 weeks' exposure, but decreased to a lesser extent the weight of the prostate and seminal vesicle.

The sperm count and percentage of motile sperm decreased and the percentage of tailless sperm in- 
creased dose-dependently (Table 2). Exposure of 2bromopropane at 1,000 ppm for 9 weeks and 3,000 ppm for 9-10 days resulted in complete loss of motile sperm and overwhelming predominance of tailless sperm at the end of the experiment. The frequency of abnormal sperm could not be assessed in the 1,000 and $3,000 \mathrm{ppm}$ groups, because very few intact sperm were detected in these groups.

Table 2. The sperm count and the percentage of motle sperm, talless sperm and abnormal sperm in the rats exposed to 2-bromopropane

\begin{tabular}{|c|c|c|c|c|c|}
\hline \multicolumn{2}{|l|}{ Group } & Control & $300 \mathrm{ppm}$ & $1,000 \mathrm{ppm}$ & $3,000 \mathrm{ppm}$ \\
\hline Number of rats & & 9 & 9 & 9 & 6 \\
\hline Sperm count & $\left(\times 10^{6} /\right.$ g cauda $)$ & $568.78 \div 20478$ & $35789=117.28^{*}$ & $326.44 \pm 13990^{* *}$ & $151.17=3439^{* *}$ \\
\hline Motile sperm & $(\%)$ & $86.16-251$ & $1583=649^{* *}$ & $0.00 \pm 000^{* *}$ & $000=000^{* *}$ \\
\hline Ta1lless sperm & $(\%)$ & $952 \perp 309$ & $5606 \pm 1219^{* *}$ & $98.28+1.30^{* *}$ & $9939=065^{* *}$ \\
\hline Abnormal sperm & $(\%)$ & $694 \pm 229$ & $2057+7.76^{* *}$ & $-\mathbf{a}$ & a \\
\hline hook up head & $(\%)$ & $154 \pm 097$ & $519 \pm 172^{* *}$ & $-\mathbf{a}$ & $-\mathbf{a}$ \\
\hline reflexed head & $(\%)$ & $3.96 \pm 168$ & $1263 \pm 5.41^{* *}$ & $-\mathbf{a}$ & $-a$ \\
\hline angular head & $(\%)$ & $0.11 \pm 033$ & $083 \pm 1.24$ & $-\mathrm{a}$ & a \\
\hline recurvant flagellum & \%) & $1.33 \pm 041$ & $193+125$ & $-a$ & $-\mathbf{a}$ \\
\hline
\end{tabular}

Values are the means=standard deviations for each group Astersks indcate that the value was significantly different from the control $\left({ }^{*} p<005\right.$. ${ }^{* *} p$. 0 01, Dunnetts' multiple comparison for sperm count, motile sperm and talless sperm and Students' t-test for abnormal sperm, hook up head, reflexed head, angular head and recurvant flagellum) a The frequency of abnormal sperm could not be assessed in the 1,000 and 3,000 ppm groups, because very few intact sperm were detected in these groups

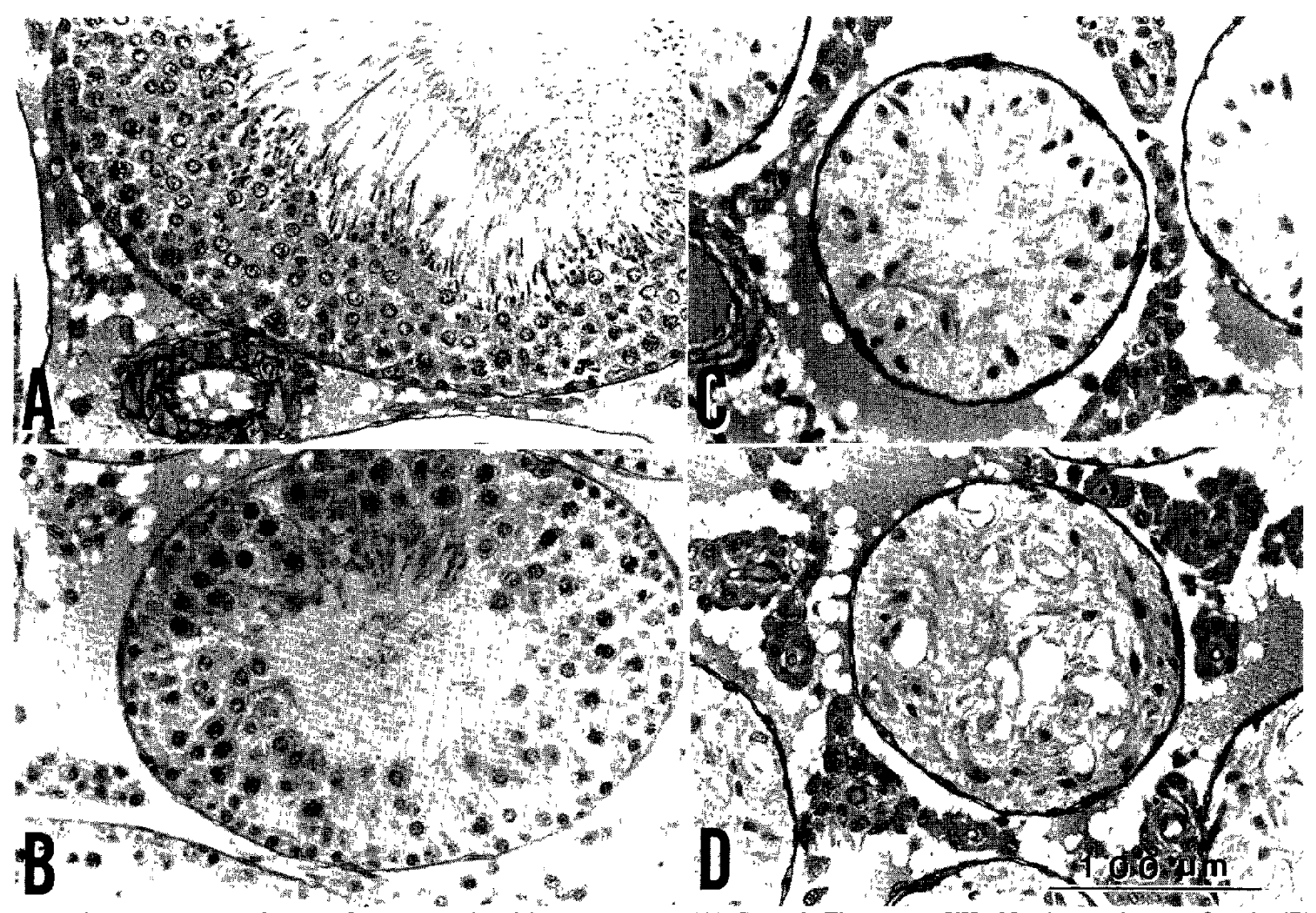

Fig. 2. Photomicrograms of testes of rats exposed to 2-bromopropane. (A) Control: The stage is VII. No abnormality was found. (B) $300 \mathrm{ppm}$ for 9 weeks: The stage is VII. The semmiferous tubule was moderately atrophed and the number of all types of germ cells decreased. (C) $1,000 \mathrm{ppm}$ for 9 weeks; All types of germ cells were absent, defined as Sertoll cell-only syndrome. Interstıtıum cells (Leydig) were hyperplastic Semınıferous tubules were severely atrophied. (D) 3,000 ppm for 10 days at the end of the experiment: The findings were the same as in (C). Periodic acid-Schiff (PAS). Scale bar indicates $100 \mu \mathrm{m}$. The magnifications of all photographs (A), (B), (C) and (D) are the same 
The percentage of abnormal sperm with hook up head and reflexed head was significantly larger in the 300 ppm group than in the control.

In the $300 \mathrm{ppm}$ group, seminiferous tubules were moderately atrophied and all types of germ cells decreased to about a half of the control (Fig. 2B). In the $1,000 \mathrm{ppm}$ group and the six surviving rats in the 3,000 ppm group, germ cells were completely lost and seminiferous tubules severely atrophied (Figs. 2C and 2D). On the other hand, Sertoli cells still remained in these exposed rats(Figs. 2B, 2C and $2 \mathrm{D}$ ). Leydig's interstitial cells were hyperplastic to a slight extent in the $300 \mathrm{ppm}$ group and to a moderate extent in the $1,000 \mathrm{ppm}$ group and the six surviving rats in the $3,000 \mathrm{ppm}$ group (Figs. 2C and 2D).

In three rats in the $3,000 \mathrm{ppm}$ group sacrificed after 11 days' exposure, spermatogonia was absent and the number of spermatocytes decreased (Fig. 3 ). In two of the three rats, some seminiferous epithelial cells (probably spermatocytes) had pyknotic nuclei. Sertoli cell vacuolation was much more marked in these two rats than in the rats in all exposed groups sacrificed at the end of the experiment. Multinucleate giant cell-like structures were found in the $300 \mathrm{ppm}$ group.

The number of sperm decreased in the epididymal duct in all the exposed groups. Prostate and seminal vesicles showed only slight atrophic change in the exposed groups. No abnormal findings were observed in the liver or kidney in any exposed groups.

Exposure to 2-bromopropane decreased erythrocytes, hemoglobin, hematocrit, platelets and leucocytes (Table 3 ). These indices decreased to a lesser degree in the six surviving rats exposed to 3,000 ppm for 9-10 days than in the 1,000 ppm group (Table 3). In the $300 \mathrm{ppm}$ group, erythrocytes and platelets significantly decreased in comparison with the control, but leucocytes, hematocrit and hemo-

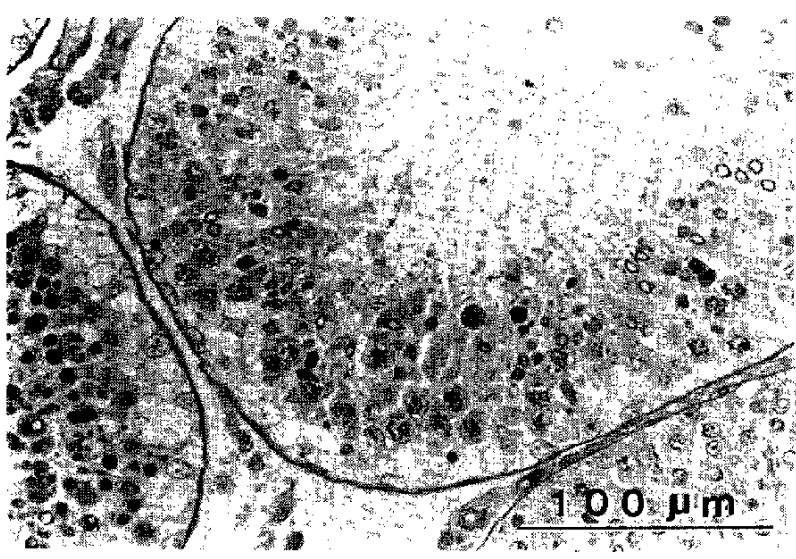

Fig 3. Photomicrogram of testes in 3,000 ppm group sacrificed 16-17 hours after 11 days' exposure. Spermatogonia were not found and Sertoli cells were vacuolated. Some seminiferous epithelial cells (probably spermatocytes) had pyknotic nuclei. Periodic acid-Schiff (PAS). Scale bar indicates $100 \mu \mathrm{m}$

globin did not (Table 3). The anemia was classified as macrocytic. Histopathological examination showed hypocellular and fatty bone marrow in the $1,000 \mathrm{ppm}$ and $3,000 \mathrm{ppm}$ groups at the end of the experiment and in the three rats in the $3,000 \mathrm{ppm}$ group which were sacrificed after 11 days' exposure.

\section{Discussion}

Oligozoospermia and anemia found in human cases were reproduced in the present animal experiment. The changes in sperm indices were accompanied by weight loss of the testis and epididymis and loss of testicular germ cells. The changes in hematological indices were accompanied by hypocellular bone marrow at $1,000 \mathrm{ppm}$ or over. It should be noted that the testicular and epididymal changes mentioned above and changes in some hematological indices were caused by inhalation exposure to $300 \mathrm{ppm}$ or higher concentrations

Table 3. The hematological indices in rats exposed to 2-bromopropane

\begin{tabular}{|c|c|c|c|c|c|}
\hline & & Control & $300 \mathrm{ppm}$ & $1,000 \mathrm{ppm}$ & $3,000 \mathrm{ppm}$ \\
\hline Number of rats & & 9 & 9 & 9 & 6 \\
\hline Erythrocyte & $\left(\times 10^{4} / \mu l\right)$ & $920.33=24.17$ & $882.78=20.63^{* *}$ & $806.67 \pm 21.77^{* *}$ & $833.50 \pm 18.75^{* *}$ \\
\hline Hemoglobin & $(\mathrm{g} / \mathrm{d} I)$ & $16.08=0.39$ & $16.10=0.33$ & $15.22 \pm 0.36^{* *}$ & $15.67 \pm 0.40$ \\
\hline Hematocrit & $(\%)$ & $46.03-0.92$ & $46.20=0.65$ & $44.02 \pm 1.17^{* *}$ & $45.50 \pm 1.39$ \\
\hline $\mathrm{MCV}$ & (fi) & $50.03=0.66$ & $52.34=0.82^{* *}$ & $54.60 \pm 1.35^{* *}$ & $54.58 \pm 0.75^{* *}$ \\
\hline $\mathrm{MCH}$ & (pg) & $17.47=0.25$ & $18.24=0.30^{* *}$ & $18.89 \pm 0.43^{* *}$ & $18.80 \pm 0.30^{* *}$ \\
\hline $\mathrm{MCHC}$ & (\%) & $34.93-0.33$ & $34.84 \pm 0.41$ & $34.58 \pm 0.37$ & $34.43 \pm 0.35^{*}$ \\
\hline Platelet & $\left(\times 10^{4} / \mu l\right)$ & $90.38=3.45$ & $78.99+7.01^{* *}$ & $65.72 \pm 7.14^{* *}$ & $82.33 \pm 6.56$ \\
\hline Leucocyte & $\left(\times 10^{2} / \mu l\right)$ & $117.44+34.46$ & $128.56+33.67$ & $72.22 \pm 9.65^{* *}$ & $91.33 \pm 20.07$ \\
\hline
\end{tabular}

Values are the means \pm standard deviations for each group. Asterisks indicate that the value was significantly different from the control ( $\mathrm{p}^{*} 0.05$, ${ }^{* *} \mathrm{p}<$ 0.01 , Dunnetts' multiple comparison). 
of 2-bromopropane. On the other hand, liver and kidneys showed little change in their weights and no pathological findings. These results show that the adverse effects of 2-bromopropane on the reproductive system and hematopoiesis may be organspecific.

Cessation of exposure at $3,000 \mathrm{ppm}$, which was not planned beforehand, resulted in demonstrating the effects of 2-bromopropane 53-54 days after the short term exposure. In the six surviving rats in the $3,000 \mathrm{ppm}$ group, the hematological indices seemed to recover to a moderate degree, whereas testicular and epididymal weights, sperm indices and the cellularity of testicular germ cells still remained almost equal to or a little less than those in the $1,000 \mathrm{ppm}$ group. These results suggest that hematopoiesis may be less vulnerable to 2bromopropane or more reversible than spermatogenesis. The results may coincide with the Korean report that showed some cases of oligozoospermia without anemia but no cases of anemia without oligozoospermia").

The absence of germ cells with remaining Sertoli cells in the 1,000 ppm group and the surviving rats in the $3,000 \mathrm{ppm}$ group is called the Sertoli cell-only syndrome. 2-Bromopropane may have a selective toxic effect on the spermatogonia, as demonstrated in the rats sacrificed shortly after cessation of 3,000 ppm exposure. The specific toxic effect of 2bromopropane on spermatogonia and hematopoietic cells suggests that differentiation and frequent dividing of cells could be involved with the toxicity.

Sertoli cell vacuolations may be an early change accompanying progressive degeneration and exfoliation of germ cells, because this change was much more noticeable in the rats in $3,000 \mathrm{ppm}$ group sacrificed after 11 days' exposure than in the six surviving rats in the $3,000 \mathrm{ppm}$ group at the end of the experiment. The Sertoli cell vacuolations were also reported as an early change following the administration of other agents to rats ${ }^{9}{ }^{15}$.

Hyperplasia of Leydig cell is generally observed as a compensatory reaction to disruption of seminiferous epithelium.

In the Korean case, it was reported that the workers could be exposed to 2-bromopropane at more than 4,000 ppm as short-term exposure ${ }^{1)}$. Ambient concentrations of 2-bromopropane were detected from $9.2 \mathrm{ppm}$ to $19.6 \mathrm{ppm}$ in the workplace during regular operation after improvement of ventilation. The real exposure concentrations were not evaluated in the field survey, but $300 \mathrm{ppm}$ to $3,000 \mathrm{ppm}$ exposure could have been possible in the Korean workplace judging from the above data. Absorption through the skin may also be responsi- ble for the uptake of 2-bromopropane into workers ${ }^{13}$, but this was not investigated in the present study.

Clinical information concerning the toxicity of 2bromopropane has been lacking thus far. The reason for this may be that this chemical has been mainly used in a closed system, wherein it was almost always an intermediate in the production of other chemicals, and therefore workers were not exposed to large dose of 2-bromopropane to produce its specific toxicity. 2-Bromopropane came to be used as a substitute for chlorofluorocarbone, since this chemical is nonflammable and volatile like chlorofluorocarbons and is easily broken down in the environment and is less destructive to the ozone layer. As a large amount of 2-bromopropane is used now and in the future the amount used in industry may rapidly increase, urgent measures must be taken to minimize 2-bromopropane exposure in workplaces. It should also be noted that numerous kinds of harmful new or existing chemicals can be introduced into workplaces with the progress of technology ${ }^{16)}$ or by social regulation of chemical production, even if intended to protect the earth's environment or workers' health.

In conclusion, 2-bromopropane was revealed to have a testicular and hematopoetic toxicity in male rats. The oligozoospermia and anemia in human cases were experimentally confirmed in rats.

Acknowledgments: We gratefully acknowledge the helps of Mr. Hisakazu Iwai and Mr. Kazuhito Ichikawa (Safety Assessment Laboratory, Sanwa Kagaku Kenkyusho Co., Ltd., Japan) and the advice of Mr. Shunji Aman (Nanyo Laboratory, Tosoh Co., Japan). We also thank Tosoh Co., Japan for a kind gift of 2-bromopropane.

\section{References}

1) Industrial Health Research Institute, Korea Industrial Safety Corporation. Final report of epidemiological survey on Yangsan LG Electronics. 1995 (in Korean).

2) Liublina E, Rabotnikova L. Comparative evaluation of acute toxcity of certain brominated hydrocarbons. Gigiena Truda i Professionalnye Zabolevaniia, 1974 Apr 18(4): 55-7(in Russian).

3) Ichihara G, Asaeda N, Kumazawa T, et al. Testicular toxicity of 2-bromopropane. J Occup Health 1996; 38: 205-206.

4) Kim H, Chung Y, Yi K, Kim J, Yu I. LC50 of 2bromopropane. Ind Health 1996; 34: 403-407.

5) Takeuchi Y, Huang J, Shibata E, Hisanaga N, Ono Y. A trial to automatize an organic solvent exposure system for small animals. Jpn J Ind Health 1989; 31 : 722 (in Japanese).

6) Huang J, Kato $K$, Shibata $E$, Hisanaga $N$, Ono $Y$, Takeuchi $Y$. Effects of subacute toluene exposure on 
neuronal and glial marker proteins in rat brain Toxicol 1990; 61: 109-117.

7) Wyrobek A, Bruce W. Chemical induction of sperm abnormalities in mice. Proc Natl Acad Sci USA $1975 ; 72: 4425-4429$.

8) Eyden B, Maisin J. Observations on the structure and levels of expression of murine spermatozoan abnormalities with special reference to tail deformations. Arch Anat Microsc 1978; 67: 19-30.

9) Flores M, Fawcett D. Ultrastructure effects of antispermatogenic compound WIN 18446 (bis dichloroacetyl diamine). Anat Rec 1972; 172: 310.

10) De Martino C, Stefanini M, Agrestini A, Cocchia D, Morrelli M, Scorza Barcellona P. Antispermatogenic activity of $1-\mathrm{p}$ chlorobenzyl-1 $\mathrm{H}$ indazol-3-carboxylic acid (AF 1321/TS) in rats. III. A light and electron microscopic study after single oral doses. Exp Mol Pathol 1975; $23: 321-356$.

11) Hoffer A, Carlton B, Brunengraber H. Ultrastructure and intercellular vacuolization of isolated perfused and control rat testes. J Androl 1983; 4 : 361-370.
12) Chapin R, Morgan K, Bus J. The morphogenesis of testicular degeneration induced in rats by orally administered 2,5-hexanedione. Exp Mol Pathol 1983; 38: 149-169.

13) Creasy D, Beech L, Gray T, Butler W. An ultrastructural study of ethylene glycol monomethyl ether-induced spermatocyte injury in the rat. Exp Mol Pathol 1986; 45: 311-322.

14) Anderson R, Berryman S, Phillips J, Feathergill K, Zaneveld L, Russell L. Biochemical and structural evidence for ethanol-induced impairment of testicular development: apparent lack of Leydig cell involvement. Toxicol Appl Pharmacol 1989; 100: 62-85.

15) Creasy D, Ford GR, Gray TJ. The morphogenesis of cyclohexylamine-induced testicular atrophy in the rat: in vivo and in vitro studies. Exp Mol Pathol $1990 ; 52(2): 155-169$.

16) Kaczmarczyk J, Paul M. Reproductive health hazards in the workplace: guidelines for policy development and implementation. Int $J$ Occup Environ Health $1996 ; 2: 48-58$. 